\title{
Rancang Bangun Aplikasi e-health Untuk Peningkatkan Pelayanan Kesehatan Pada Puskesmas Kibin
}

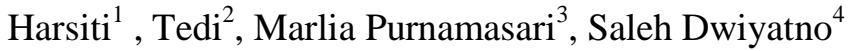 \\ 1), 2) Program Studi Sistem Informasi, ${ }^{3), 4)}$ Program Studi Teknik Informatika \\ Fakultas Teknologi Informasi, Universitas Serang Raya \\ $J l$, Raya Cilegon-Serang - Drangong Kota Serang \\ E-mail: ${ }^{1)}$ harsiti@yahoo.com, ${ }^{2)}$ tedijho@gmail.com, ${ }^{3)}$ marlia.unsera@gmail.com, \\ $\left.{ }^{4}\right)$ salehdwiyatno@gmail.com
}

\begin{abstract}
Puskemas merupakan salah satu organisasi fungsional yang berada dibawah naungan Dinas Kesehatan Kabupaten atau Kota, dimana Puskesmas ini ditujukan untuk memberikan pelayanan kepada masyarakat yang belum bisa terjangkau oleh pelayanan rumah sakit. Pelayanan yang dimaksud adalah mulai dari pendaftaran pasien baik pasien lama ataupun pasien baru, pencatatan rekam medis pasien, distribusi obat ke pasien, pengolahan data dokter dan perawat yang menangani pasien sampai sebagai bentuk keterbukaan informasi kepada masyarakat. Penelitian ini akan membangun sebuah aplikasi yang dapat melakukan berbagai fungsi pelayanan dalam bidang kesehatan (e-health) yang bertujuan agar dapat membantu dan mempermudah pelayanan di Puskesmas terkait dengan pelayanan pasien, khususnya mempermudah pasien melihat riwayat kesehatannya sendiri, serta pasien bisa mendapatkan pendidikan kesehatan. Aplikasi e-health dirancang memiliki beberapa fitur yaitu pendaftaran online, pengiriman resep, pasien bisa melihat riwayat kesehatannya selama berobat di Puskesmas dan menyediakan informasi kesehatan. Perancangan sistem e-health ini menggunakan pendekatan perencangan berorientasi pada objek menguunakan tools Unified Modelling Language (UML) yang terdiri dari lima diagram yaitu usecase diagram, activity diagram, sequence diagram, class diagram dan collaboration diagram dan pengembangan aplikasi menggunakan bahasa pemrograman PHP, database menggunakan PHPMysql dan Dreamweaver. .
\end{abstract}

Kata Kunci: Puskesmas, e-health, Unified Modelling Language

\subsection{Latar Belakang}

\section{PENDAHULUAN}

Pusat kesehatan masyarakat
(PUSKESMAS) merupakan organisasi kesehatan yang bergerak membantu fungsi rumah sakit didaerah yang belum bisa terjangkau oleh pelayanan rumah sakit, tentunya harus selalu meningkatkan kualitas pelayanan terhadap masyarakat, salah satunya dengan membangun layanan teknologi informasi dan komunikasi.

Dalam pelaksanaan seluruh kegiatan yang dilakukan di Puskesmas Kibin sudah terkomputerisasi tetapi masih terdapat kendala yang membuat kegiatannya tidak efisien. Banyak pasien yang datang membuat bagian pendaftaran kewalahan dalam melayani proses pendaftaran sehingga sering terjadinya antrian pasien di bagian registrasi yang akan mendaftar, pasien banyak membuang waktu hanya untuk menunggu giliran pendaftaran maupun pemeriksaan, kurangnya informasi kesehatan yang bisa dijadikan sebagai pendidikan yang bisa diakses atau didapat dimana saja tanpa harus datang langsung ke puskesmas, tidak adanya fasilitas layanan yang diberikan tanpa batasan jarak merupakan salah satu kekurangan dari Puskesmas Kibin

Salah satu alternative yang dapat diterapkan untuk membantu dan mempermudah pelayanan kesehatan yaitu dengan dikembangkannya aplikasi $e$-health untuk memberikan kemudahan dan meningkatkan pelayanan kesehatan pada Puskesmas Kibin. E-health dalam berbagai hal dapat meningkatkan kualitas akses ke pelayanan yang diberikan. E-health sendiri secara luas dapat bermakna bidang pengetahuan baru yang merupakan persilangan dari informasi medis, kesehatan publik dan usaha, berkaitan dengan jasa pelayanan dan informasi kesehatan yang dipertukarkan atau ditingkatkan melalui saluran internet dan teknologi. E-health ini dikembangankan secara interaktif agar terjadi komunikasi dua arah baik dari pihak puskesmas ataupun pasien.

Perancangan aplikasi e-health untuk peningkatan pelayanan kesehatan pada sebuah puskesmas di wilayah Kecamatan Kibin Kabupaten Serang - Banten, menggunakan 
pendekatan berorientasi objek dengan menggunakan tools Unified Modelling Language (UMUL). Dalam rancangan digunakan lima diagram yaitu usecase diagram, activity diagram, sequence diagram, class diagram dan collaboration diagram. Aplikasi yang dibangun akan membantu meningkatkan pelayanan kesehatan, mempermudah pasien dalam memperoleh informasi, dan mendapatkan pendidikan kesehatan sehingga dapat memperoleh pengetahuan dalam pencegahan dan penanganan penyakit.

\subsection{Tinjauan Pustaka}

Dalam penelitian ini meruju pada penelitian yang terkait dengan $e$-health, adapun beberapa penelitian sebelumnya yang pernah dilakukan diantaranya: Aplikasi dasar yang ada dalam e-health antara lain pencatatan dan pelaporan data pasien, basis data dan evaluasi pelayanan kesehatan, telekonsultasi sederhana, dan pendidikan medis jarak jauh (Prof. Soegijardjo Soegijoko, 2010). Pada bidang yang sama namun lebih dikhususkan untuk klinik di Balai Pengobatan Kantor Kementrian Pertanian, telah dibuat prototipe $e$-klinik berbasis web yang memiliki manfaat keamanan data, bisa diakses dari berbagai tempat sehingga memperkecil kemungkinan hilangnya data dan memperlancar prosedur yang ada (Tri pujadi, 2010). Pada Klinik Sehat Budi Luhur juga dibangun aplikasi $e$-health yang dapat mempermudah dokter dalam mendiagnosis penyakit pasien karena data rekam medis yang diperoleh lengkap (Emil Solecha, 2012). ehealth merupakan solusi enterprise bidang kesehatan karena melibatkan banyak pihak mulai dari masyarakat sampai dengan produsen obat (Achmat Supriyatno dan Muchammad Romzi, 2006). Pada Klinik Bersalin Bidan Maryati Sudiro telah dibangun aplikasi $e$ health untuk mempermudah dalam memberikan pelayanan kesehatan terhadap masyarakat khususnya wanita hamil dan memberikan solusi bagi permasalahan kehamilan, keluarga berencana, persalinan dan hal - hal tentang kebidanan (Arif Wibowo, 2013). Pembangunan Cloud E-health di Dinas Kesehatan Provinsi Jawa Barat mempermudah rumah sakit yang ingin memiliki website dengan kemudahan yang diberikan, mulai dari proses pendaftaran sampai dengan proses pengolahan data dan informasi didalamnya, sehingga pegawai kesehatan tidak lagi memerlukan infrastruktur yang besar untuk membuat suatu website serta investasi perangkat keras, perangkat lunak, maintenance, dan upgrading (Irvie Miria Sasube, 2013)

Itulah beberapa tinjauan penelitian yang dikaji untuk menambah referensi, mengingat $e$ health sangat berperan dalam meningkatkan kualitas pelayanan masyarakat dan peluang penggunaan e-health dalam membantu memecahkan masalah pelayanan kesehatan masyarakat menjadi sangat besar.

\section{METODE PENELITIAN}

Penelitian ini diawali dengan tahap perencanaan perancangan sistem e-health dengan melakukan survey terhadap objek penelitian. Selanjutnya dilakukan proses analisa kebutuhan system meliputi analisa kebutuhan funsionalitas sistem, analisa penguna sistem dan analisa kebutuhan software dan hardware. Tahap perancangan sistem meliputi : diagram use case, activity diagram, sequence diagram, collaboration diagram, class diagram dan entitas relationship diagram. Kegiatan selanjutnya adalah tahapan implementasi dengan mengembangkan aplikasi menggunakan bahasa pemrograman PHP dan Dreamweaver.

\section{HASIL DAN PEMBAHASAN}

\subsection{Perancangan Sistem}

Perancangan sistem adalah menggambarkan bagaimana sebuah sistem dibentuk agar dapat memberikan gambaran yang jelas kepada pemakai/ user, dalam penggambaran sistem $e$-health ini yaitu dengan menggunakan notasi dari Unified Modelling Language (UML)..

\subsection{Use Case Diagram}

Use Case diagram digunakan bertujuan untuk menggambarkan perilaku yang dibutuhkan atau diharapkan dari sistem yang akan dikembangkan. Use case menyediakan cara untuk mendapatkan pemahaman dari apa yang diharapkan dan dibutuhkan oleh pengguna kelak. Berikut ini adalah Use case diagram untuk sistem $e$-health : 


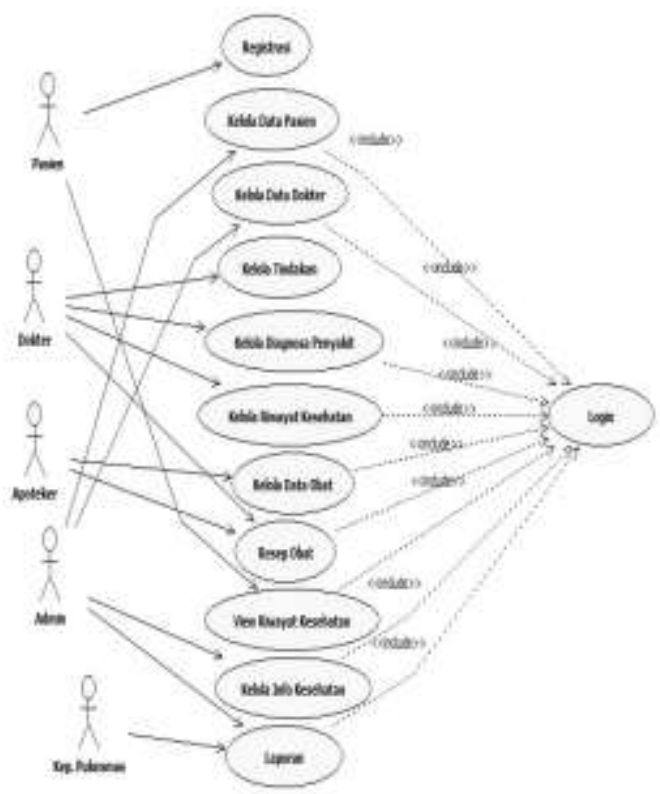

Gambar 1. Use Case diagram E-health

\subsection{Hasil}

Hasil aplikasi yang ditampilkan pada paper ini adalah halaman aplikasi yang berisi info kesehatan dan informasi riwayat kesehatan pasien. Untuk bisa melihat informasi riwayat kesehatannya sendiri, pasien harus memasukan username dan password yang sebelumnya di peroleh ketika pasien melakukan registrasi pada aplikasi $e$-health. Info kesehatan berisikan pengenalan penyakit dan pencegahan sehingga pasien bisa mendapatkan pendidikan didalamnya (contoh tampilan info kesehatan Gambar 2)

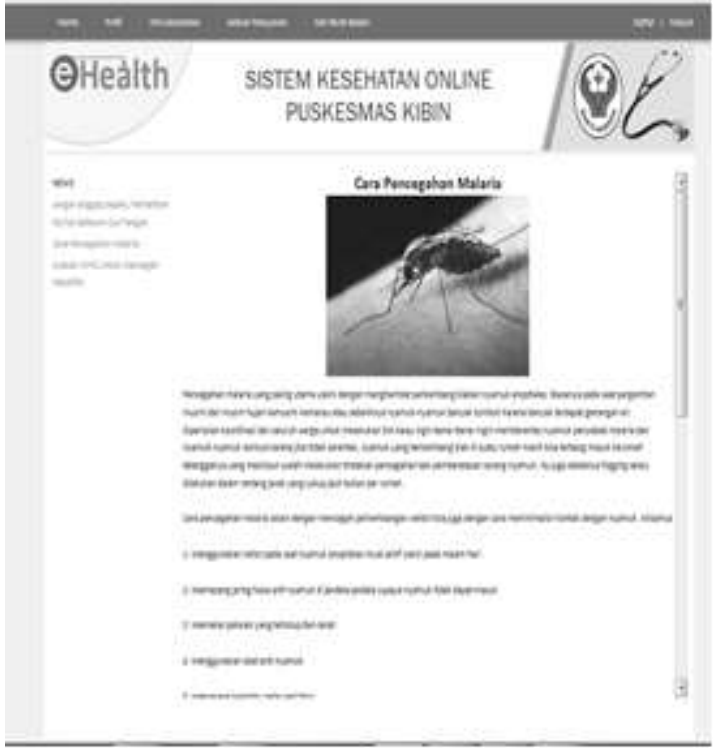

Gambar 2. Tampialan Info Kesehatan
Untuk mengetahui riwayat kesehatannya sendiri selama pasien berobat dipuskesmas, maka diharuskan pasien melakukan registrasi dan konfirmasi kebagian pendaftaran, berikut merupakan tampilan riwayat kesehatan pasien yang diakses.

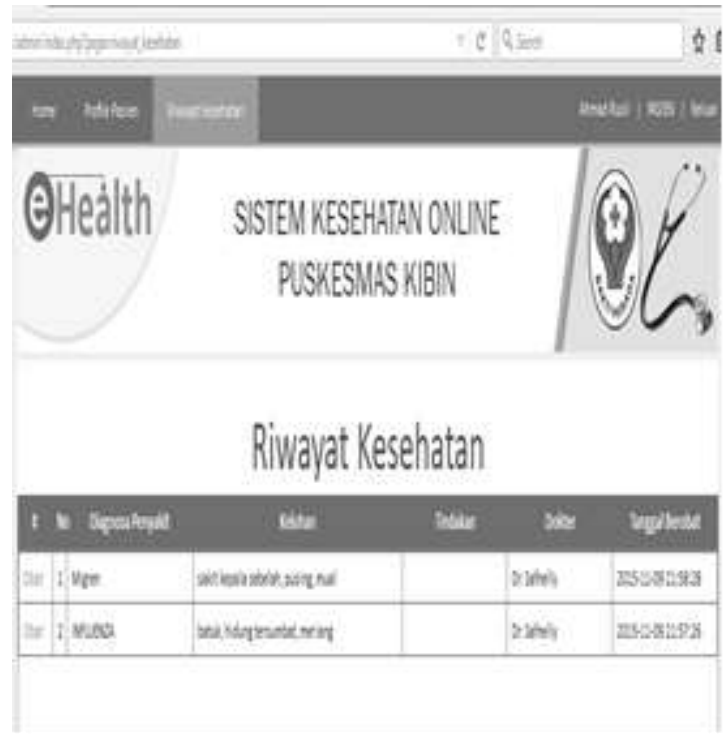

Gambar 3. Tampilan Riwayat Kesehatan

\section{KESIMPULAN DAN SARAN}

V.

Berdasarkan hasil penelitian yang telah dilakukan dalam perancangan sistem $e$ health untuk peningkatan pelayanan pada Puskesmas Kibin, maka dapat ditarik kesimpulan sebagai berikut:

a. Dalam perancangan sistem $e$-health ini diawali dengan tahap perencanaan sistem dengan melakukan survey terhadap objek penelitian. Selanjutnya dilakukan proses analisa kebutuhan sistem untuk dibuatkan fungsionalitas sistem, kemudian dibuat diagram pendukung perancangan sistem, meliputi : diagram use case, activity diagram, sequence diagram, class diagram, collaboration diagram, dan entitas relation diagram, kegiatan selanjutnya adalah membuat aplikasi $e$ health menggunakan bahasa pemrograman PHP, dengan desain Dreamweaver, dan appserv sebagai databasenya. Sehingga menjadi sebuah aplikasi e-health yang dapat mempermudah pasien melakukan registrasi online, memberikan informasi tentang kesehatan yang bisa dijadikan pendidikan bagi masyarakat, dan dapat diakses dimana saja karena aplikasi ini terkoneksi lewat internet. 
b. Pada aplikasi $e$-health ini juga terdapat sistem pencatatan yang berisikan semua informasi tentang identitas dan riwayat pasien selama menerima pelayanan medis di Puskesmas, laporan rekam medis yang bisa diakses oleh pasien sebagai keterbukaan informasi kepada pasien tentang apa yang di deritanya.

\section{REFERENCES}

[1] Acmat Supriyatno,Muchamad Romzi. (2006). Ehealth Solusi Enterprise Bidang Kesehatan Berbasiskan Open Source, Prosiding Konferensi Nasional Teknologi Informasi \& Komunikasi untuk Indonesia.

[2] Inasari Widyastuti. (2008). Analisa Aplikasi EHealth Berbasis Website di Instansi Kesehatan Pemerintah dan Swasta serta Potensi Implementasinya di Indonesia. Jurnal Penelitian Ilmu Pengetahuan dan Teknologi Komunikasi Vol 10 No. 2, Desember.

[3] Prof. Soegijardjo Soegijoko. (2010). Perkembangan Terkini Telemedika dan E-health serta Prospek Aplikasinya di Indonesia, Seminar Nasional Aplikasi Teknologi Informasi 2010 (SNATI 2010).

[4] Gideon, Silvy, Dharma, Nilo., Perancangan Ehealth Sistem Telemedicine Penyakit Dalam Untuk Praktisi Kesehatan,

[5] Tri pujadi. (2010) Prototipe E-Klinik Untuk Layanan Kesehatan Berbasis Web Pada Balai Pengobatan Kantor Pusat Kementrian Pertanian, ComTech Vol.1 No.1 Juni 2010: 157-169,

[6] Harsiti, Tb Ai Munandar, Roy.(2012) Perancangan Sistem Informasi Catatan Hasil Diagnosis Penyakit pada Pasien Pusat Kesehatan Masyarakat, Prosiding Seminar Nasional Teknikom 2012.

[7] Solecha, Emil, 2012, "Pembangunan Aplikasi Ehealth pada Klinik Sehat Budi Luhur". Skripsi pada Unikom. Diterbitkan

[8] Sasube, Irvie Miria, 2013, "Pembangunan Infrastruktur Cloud Computing E-health Sebagai Layanan Pengolahan Informasi Kesehatan di Dinas Kesehatan Provinsi Jawabarat". Skripsi pada Unikom. Diterbitkan

[9] Wibowo, Arif, 2013, "Pemangunan Aplikasi Ehealth dalam Bidang Kebidanan Berbasis Web Pada
Klinik Bersalin Bidan Maryati Sudiro". Skripsi pada Unikom. Diterbitkan.

[10] Hs, Muflihah Ana, 2010, “Tingkat Implementasi Permenkes Nomor 741/Menkes/Per/VII/2008 Tentang standar Pelayanan Minimal Bidang Kesehatan di Puskesmas Kibin Kabupaten Serang”. Skripsi pada Untirta. Diterbitkan

[11] Profil Puskesmas Kibin 2012

[12] Prasetio, Arif, 2012, Buku Pintar Pemrograman Web. Jakarta. Mediakita.

[13] Madcoms, 2011, Aplikasi Web Database dengan Dreamweaver dan Php- Mysql Yogyakarta. Andi.

[14] Nugroho, Adi, 2005, Analisa dan Perancangan Sistem Informasi dengan Metodologi Berorientasi Objek. Bandung. Informatika Bandung.

[15] Achmadi, Umar Fachmi. 2013, Kesehatan Mayarakat Teori dan Aplikasi. Jakarta. Raja Grafindo Persada.

[16] Priyadi, Yudi. 2013 Kolaborasi SQL dan ERD dalam implementasi Database. Bandung. Andi.

[17] AS,Rosa Shalahuddin. 2012 Modul Pembelajaran Rekayasa Perangkat Lunak Tersetruktur dan Berorientasi Objek. ModulaLANG.

[18] Harsiti (2011) Pengembangan Sistemm Informasi Manajeme Puskesmas (SIMPUS) Berbasis Radio Frequency Identification, Tesis Magister Komputer STMIK Eresha Jakarta, 2011. 